\title{
Docetaxel-trastuzumab stealth immunoliposome: development and in vitro proof of concept studies in breast cancer
}

This article was published in the following Dove Press journal: International Journal of Nanomedicine

Anne Rodallec,' Jean-Michel

Brunel, ${ }^{2}$ Sarah Giacometti, '

Helene Maccario, ${ }^{3}$ Florian

Correard, ${ }^{3}$ Eric Mas, ${ }^{3}$ Caroline

Orneto, ${ }^{4}$ Ariel Savina, ${ }^{5}$ Fanny

Bouquet, ${ }^{5}$ Bruno Lacarelle,'

Joseph Ciccolini,' Raphaelle

Fanciullino'

'SMARTc Unit, Pharmacokinetics Laboratory, CRCM UMR UI068 CNRS UMR 7258 Aix Marseille Université, Marseille, France; ${ }^{2}$ CRCM CNRS UMR 7258 Aix Marseille Université, Marseille, France; ${ }^{3} \mathrm{CRO} 2$ UMR S 91। Aix Marseille Université, Marseille, France; ${ }^{4}$ Biopharmacy Laboratory, Aix Marseille Université, Marseille, France; ${ }^{5}$ Institut Roche, Boulogne Billancourt Cedex, France

Video abstract

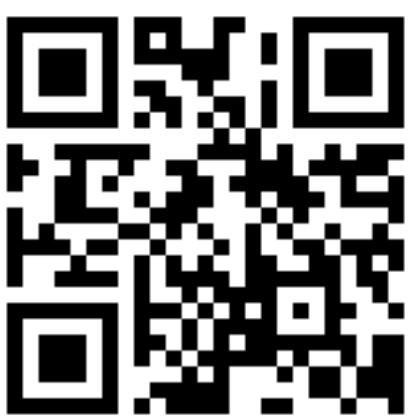

Point your SmartPhone at the code above. If you have a $Q R$ code reader the video abstract will appear. Or use: http://youtu.be/5pEEVwkt8pl

Correspondence: Raphaelle Fanciullino SMARTc Unit, CRCM UMR Inserm 1068, CNRS UMR 7258, Aix Marseille Université, 27 boulevard Jean Moulin, 13005 Marseille, France Tel +33491835541

Email raphaelle.fanciullino@univ-amu.fr
Background: Trastuzumab plus docetaxel is a mainstay to treat HER2-positive breast cancers. However, developing nanoparticles could help to improve the efficacy/toxicity balance of this doublet by improving drug trafficking and delivery to tumors. This project aimed to develop an immunoliposome in breast cancer, combining docetaxel encapsulated in a stealth liposome engrafted with trastuzumab, and comparing its performances on human breast cancer cell lines with standard combination of docetaxel plus trastuzumab.

Methods: Several strategies to engraft trastuzumab to pegylated liposomes were tested. Immunoliposomes made of natural (antibody nanoconjugate-1 [ANC-1]) and synthetic lipids (ANC-2) were synthesized using standard thin film method and compared in size, morphology, docetaxel encapsulation, trastuzumab engraftment rates and stability. Antiproliferative activity was tested on human breast cancer models ranging from almost negative (MDA-MB-231), positive (MDA-MB-453) to overexpressing (SKBR3) HER2. Finally, cell uptake of ANC-1 was studied by electronic microscopy.

Results: ANC-1 showed a greater docetaxel encapsulation rate $(73 \% \pm 6 \%$ vs $53 \% \pm 4 \%)$ and longer stability (up to 1 week) as compared with ANC-2. Both ANC presented particle size $\leq 150 \mathrm{~nm}$ and showed similar or higher in vitro antiproliferative activities than standard treatment, ANC-1 performing better than ANC-2. The $\mathrm{IC}_{50 \mathrm{~s}}$ for docetaxel combined to free trastuzumab were $8.7 \pm 4,2 \pm 0.7$ and $6 \pm 2 \mathrm{nM}$ with MDA-MB-231, MDA-MB-453 and SKBR3, respectively. The $\mathrm{IC}_{50 \mathrm{~s}}$ for ANC-1 were $2.5 \pm 1,1.8 \pm 0.6$ and 3.4 $\pm 0.8 \mathrm{nM}$ and for ANC-2 were $1.8 \pm 0.3 \mathrm{nM}, 2.8 \pm 0.8 \mathrm{nM}$ and $6.8 \pm 1.8 \mathrm{nM}$ with MDA-MB-231, MDA-MB-453 and SKBR3, respectively. Cellular uptake appeared to depend on HER2 expression, the higher the expression, the higher the uptake.

Conclusion: In vitro results suggest that higher antiproliferative efficacy and efficient drug delivery can be achieved in breast cancer models using nanoparticles.

Keywords: immunoliposomes, biopharmaceutical development, breast cancer, docetaxel, trastuzumab, HER2

\section{Introduction}

Taxanes are a mainstay in the treatment of several solid tumors including breast cancer. ${ }^{1}$ By interfering with spindle dynamics, they stabilize microtubules and cause cell cycle arrest at the metaphase/anaphase, resulting in cell apoptosis. In vitro, docetaxel is generally twofold to fourfold more potent than paclitaxel. ${ }^{2}$ This greater tumor activity was confirmed at bedside in metastatic breast cancer. ${ }^{3}$ However, docetaxel patients display more severe hematological and non-hematological toxicities (eg, neutropenia, thrombocytopenia, stomatitis, asthenia) than paclitaxel patients. ${ }^{3}$ In addition, common 
drug-related toxicities are hypersensitivity reactions related to the solubilizing agents necessary to allow taxanes to be given as infusions. ${ }^{4,5}$ In this respect, incorporating taxanes into nanoparticles could help limiting treatment-induced toxicities, by skipping the use of solubilizing agents and sparing healthy tissues while better targeting tumor cells. ${ }^{6}$ Consequently, many liposomes and stealth liposomes have been developed, and have shown both in vitro and in vivo less toxicity with equivalent or higher efficacy against tumors. ${ }^{7,8}$ Similar better outcomes were evidenced when tested in clinical trials, either alone or in combination. ${ }^{9-11}$ However, unlike doxorubicin forms, no liposomal docetaxel has been approved yet in breast cancer. Therefore, although the first or second generation of liposomes displayed improved pharmacokinetics (ie, decreased clearance and higher tumor accumulation), ${ }^{12-14}$ further development of nanoparticles is still an ongoing story with taxanes. Thus, more sophisticated forms have been developed such as co-loaded liposomes (eg, docetaxel + palmitoyl ascorbate, ${ }^{15}$ paclitaxel + rapamycin, ${ }^{16}$ docetaxel + BCL-2 SiRNA ${ }^{17}$ ), triggered liposomes (eg, $\mathrm{pH}$ sensitive ${ }^{18}$ or thermosensitive ${ }^{19}$ ) and targeted liposomes. Many moieties (eg, small-molecule ligands, peptides ${ }^{20}$ and monoclonal antibodies) have been used over the last years to actively target cancer cells through different strategies, including targeting several receptors like folate receptors, ${ }^{21,22}$ integrin ${ }^{23}$ and transferrin. ${ }^{24,25}$ In the early 2010s, an immunoliposome of doxorubicin engrafted with anti-epidermal growth factor receptor cetuximab was developed and reached early Phase I clinical trials, although this combination had no clear application in breast cancer. ${ }^{26}$ However, this seminal study demonstrated that it was possible to target an external receptor expressed on cancer cell surface using a monoclonal antibody engrafted on a nanoparticle. Overexpressed in $20 \%-40 \%$ of breast cancers, ${ }^{27}$ human epidermal growth factor receptor-2 (HER2) is an attractive receptor likely to help targeting of nanoparticles loaded with cytotoxics. MM302, a stealth liposomal formulation of doxorubicin coated with an anti-HER2 antibody, showed appealing results when tested in early clinical studies, ${ }^{28}$ but unfortunately subsequent Phase II trial failed in confirming the promising Phase I results because of poor efficacy and futility. ${ }^{29}$ With MM302, targeting HER2 was achieved using a lab-synthesized anti-HER2 antibody. Of note, the approval of the anti-HER2 monoclonal antibody trastuzumab (Herceptin $^{\circledR}$ ), in the early 2000 s has considerably improved the poor clinical outcome and survival of HER2+ breast cancer patients, when associated with docetaxel. ${ }^{29-31}$ Thus, developing directly a trastuzumab-coated liposomal taxane represents a promising and convenient strategy in breast cancer, rather than using home-made antibodies, as trastuzumab is a well-known and fully characterized antibody. ${ }^{32}$

In this study, we present the early development of such novel entity, combining stealth liposomal docetaxel with engrafted trastuzumab on its surface. Two formulations of liposomes with several engraftment techniques were tested: neutral formulation using phosphatidylcholine (antibody nanoconjugate-1 [ANC-1]) or positive formulation using 1,2dioleoyl-3-trimethylammonium-propane (DOTAP; ANC-2). Performances of the two resulting immunoliposomes were next compared in terms of physical characteristics, stability and antiproliferative efficacy in human breast cancer models varying in HER2 expression levels (Figure 1).

\section{Materials and methods Cell lines}

Experiments were carried on three human breast cancer cell lines: SKBR3 (strong HER2 overexpression), MDA-MB-453 (HER2 overexpression) and MDA-MB-231 (HER2 mild expression). Cells were purchased from the American Type Culture Cell. Cells were cultured in RPMI supplemented with $10 \%$ FBS, $1 \%$ penicillin and $0.16 \%$ kanamycin and grown in a humidified $\mathrm{CO}_{2}$ incubator at $37^{\circ} \mathrm{C}$. Cells were regularly authenticated on cell viability, morphology and doubling time.

\section{Drugs and chemicals}

Egg yolk phosphatidylcholine (PC), phosphatidylglycerol (PG), cholesterol (Chol), 1,2-distearoyl-sn-glycero-3-phosphoethanolamine and paclitaxel were purchased from Sigma (St-Quentin-Fallavier, France). 1,2-Distearoyl-sn-glycero3-phosphoethanolamine-N-[maleimide(polyethylene glycol)-2000] (Mal-PEG) and DOTAP were purchased from COGER (Paris, France). Docetaxel was purchased from VWR (Fontenay-sous-Bois, France). DIR, a fluorophore tag, was purchased from Caliper (Villebon-sur-Yvette, France). 2-Iminothiolane (Traut's reagent) and Draq5 were purchased from Fisher Scientific (Illkirch-Graffenstaden, France). QuantiBRITE phycoerythrin (PE) and PE Mouse Anti-Human HER-2/neu were purchased from BD Biosciences (San Jose, CA, USA). Trastuzumab (Herceptin) was kindly given by Genentech (South San Francisco, CA, USA). All other reagents were of analytical grade.

\section{Pegylated liposome preparation}

Two compositions of liposomes were studied: Mal-PEG and docetaxel. Liposome-1 used PC, PG and Chol, whereas 

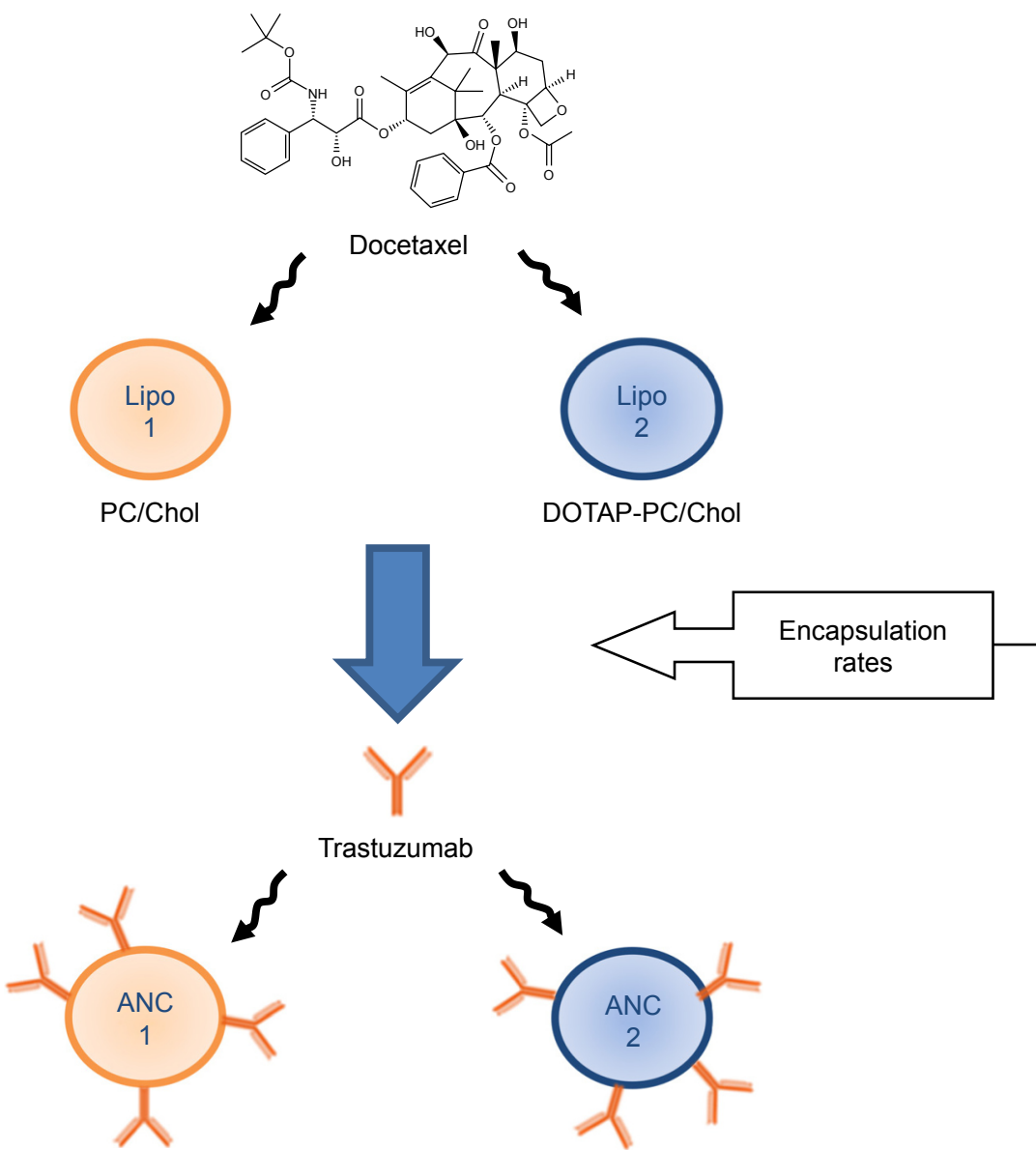

Trastuzumab
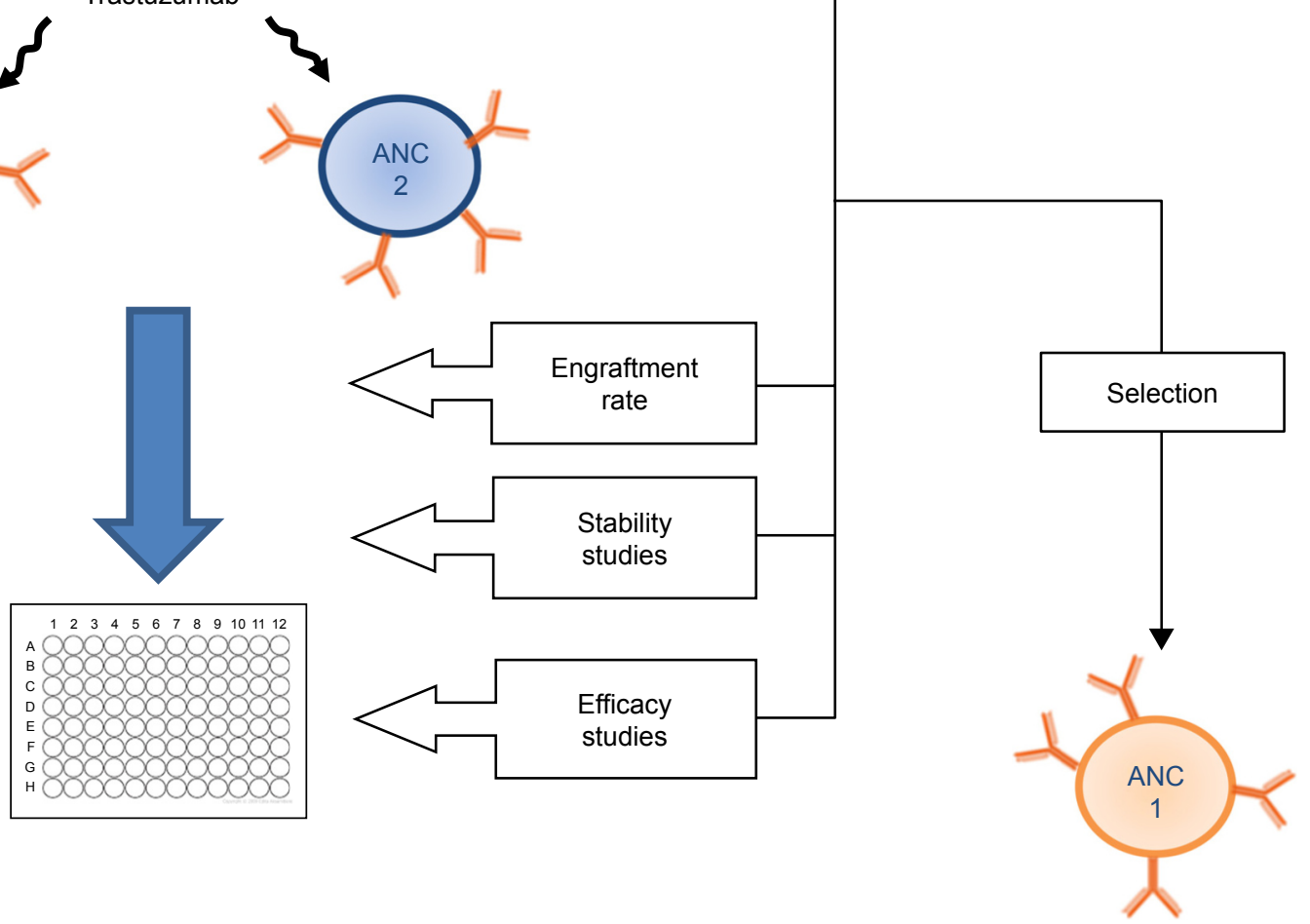

Figure I Formulation and testing of two different nanoparticles.

Abbreviations: Lipo, liposome; PC, phosphatidylcholine; Chol, cholesterol; DOTAP, I,2-dioleoyl-3-trimethylammonium-propane; ANC, antibody nanoconjugate.

Liposome-2 used DOTAP with PC or Chol. Both compositions were synthesized using the classic thin-film method. ${ }^{33}$ Briefly, lipids were dissolved in methanol. Lipidic solution was further mixed with DIR as fluorophore when required. Methanol was then removed by rotary evaporation (Laborota 4003 , Heidolph Instruments) at $38^{\circ} \mathrm{C}$ to avoid toxicity. After 30 minutes, a thin lipid film was obtained. To remove the residual solvent, lipid film was dried under stream of nitrogen for 2 hours at room temperature. The film was then hydrated with a 5\% vol/vol glucose solution, and MLV liposomes were obtained. Several strategies were performed to reduce and homogenize liposomes in size. Extrusion through 400, 200, 100 and $80 \mathrm{~nm}$ polycarbonate pore membranes (Nuclepore, Whatman France) using a LipoFast LF-50 or alternatively 
$20 \mathrm{kHz}$ sonication on ice for 5 minutes at $4^{\circ} \mathrm{C}$ using a Branson Sonifier 250 sonic probe were tested. ${ }^{34,35}$

\section{Pegylated immunoliposome preparation: antibody engraftment}

Trastuzumab engraftment was performed from previously obtained Liposome-1 and Liposome-2, generating immunoliposomes made of PC (ie, ANC-1) or DOTAP \pm PC or Chol (ie, ANC-2). In addition, two different engraftment strategies ${ }^{36}$ were tested. Strategy A targeting the amine function relied on increasing the $\mathrm{pH}$ of the liposome solution with the addition of $\mathrm{NaOH}$. Two alternative modalities of $\mathrm{NaOH}$ addition were further tested: during the hydration step of the lipid film and after the extrusion step. Once extruding $\mathrm{pH}$ was $>8.5$ for liposome solution, trastuzumab was added in 1:65 molar ratio (trastuzumab: Mal-PEG). The mixture was then kept under constant overnight shaking. Alternatively, strategy B targeting the thiol function ${ }^{36-38}$ required a preliminary step of trastuzumab thiolation. To this end, trastuzumab was first dissolved in a $0.1 \mathrm{M}$ sodium phosphate-buffer saline (PBS), pH 8.0, containing $5 \mathrm{mM}$ ethylenediaminetetraacetic acid and mixed under constant shaking, for 2 hours at room temperature with a Traut's reagent solution at 1:10 molar ratio (Traut's: trastuzumab). Thiolated trastuzumab was then directly mixed with the pegylated liposomes at 1:127 molar ratio (trastuzumab: MAL-PEG). The mixture was kept under constant shaking at $4^{\circ} \mathrm{C}$ overnight. For both strategies, unbound trastuzumab and free docetaxel were removed from the liposomal solution using 6,000 $\mathrm{g}$ centrifugation on MWCO 300 KDa vivaspins (VWR). ${ }^{39,40}$

\section{Size and polydispersity study}

Size and polydispersity index (PDI) were measured by light scattering (LDS). Liposomes and immunoliposomes were diluted in a PBS solution and then analyzed by a Zeta sizer Nano S (Malvern Instruments, Malvern, UK). Liposomal preparations were considered unimodal for a PDI $<0.2 .{ }^{41,42}$

\section{Docetaxel encapsulation rate and entrapment efficiency}

Docetaxel concentrations were measured using a validated high pressure liquid chromatography-UV method ${ }^{43}$ after liquid/liquid extraction and using a C18 column ( $25 \mathrm{~cm} \times 4.6 \mathrm{~mm}, 5 \mu \mathrm{m}$, Waters, Guyancourt, France). The mobile phase was composed of $53 \%$ of ammonium acetate buffer (35 nM, pH 5) and 47\% of acetonitrile. Samples were eluted at a constant flow rate of $1.8 \mathrm{~mL} / \mathrm{min}$ with UV detection (227 nm). Analysis was performed on an Agilent 1100 liquid chromatography system. Data were acquired and analyzed using Chemstation software (Agilent, Les Ulis, France). Docetaxel and paclitaxel typical retention times were 11 and 13.5 minutes, respectively. Encapsulation rate for docetaxel was calculated using the following formula:

$$
\text { Encapsulation rate }=\frac{\mathrm{mg} \text { DOCE HPLC measured }}{\mathrm{mg} \text { DOCE initially used }} \times 100 \text {. }
$$

Entrapment efficiency for docetaxel was calculated using the following formula:

$$
\begin{aligned}
& \text { Entrapment efficiency } \\
& \qquad=\frac{\mathrm{mg} \text { DOCE HPLC measured }}{\mathrm{mg} \text { DOCE present before centrifugation }} \times 100 .
\end{aligned}
$$

\section{Trastuzumab engraftment rate}

Sodium dodecyl sulfate (SDS) polyacrylamide gel electrophoresis was performed to show the presence and integrity of engrafted trastuzumab on liposome using polyacrylamide $10 \%$ gels, with a constant voltage of $100 \mathrm{~V}$. The running buffer was composed of Tris/glycine/SDS. The gel was stained with Coomassie blue and rinsed overnight prior analysis. Additionally, trastuzumab engraftment rate was indirectly measured by the Bradford assay, ${ }^{44}$ using thiolated trastuzumab as the reference standard.

\section{Electronic microscopy analysis}

Liposomes were diluted in PBS and dropped on a copper grid. After 15 minutes, they were stained for 5 minutes with 5\% uranyl acetate or $2 \%$ osmium tetroxide before being dried out overnight at room temperature. The grid was then observed at $80 \mathrm{kV}$ using transmission electron microscopy (JEM-1410; JEOL Ltd., Tokyo, Japan) coupled with a Megaview III camera (Soft Imaging System, Münster, Germany).

\section{Stability studies}

Stability studies were performed on several storage conditions (ie, $20 \%$ diluted ANC kept at $-20^{\circ} \mathrm{C}$, concentrated and $20 \%$ diluted ANC kept at $4^{\circ} \mathrm{C}$ and $20 \%$ diluted ANC kept at $25^{\circ} \mathrm{C}$ ), always protected from light. Liposome size, PDI, docetaxel leakage and persistence of the engrafted trastuzumab were evaluated weekly for a month, then bimonthly for up to 46 days.

\section{Quantification of HER2 on cells}

As previously described, ${ }^{45}$ QuantiBRITE PE (BD Biosciences) was used to estimate the absolute number of HER2 on cell membranes. About 100,000 cells of SKBR3, 
MDA-MB-453 or MDA-MB-231 were incubated under saturated conditions with PE Mouse Anti-Human HER-2/ neu (BD Biosciences) for 30 minutes at $4{ }^{\circ} \mathrm{C}$ before being rinsed with PBS. IgG2a-PE anti-mouse antibodies (Fisher Scientific) were used for isotopic control. Analysis was then immediately performed on Gallios Beckman Coulter. Assuming our anti-HER-2 PE antibody has a 1:1 fluorochrome: antibody ratio, we determined $\mathrm{PE}$ median fluorescence intensity (MFI) for all cell lines and reported it on a log-log graph with MFI vs PE molecules, after subtracting isotopic control MFI. Of note, to avoid PE signal saturation, adjustment of QuantiBRITE in low sensitivity conditions was performed on SKBR3 cells.

\section{In vitro antiproliferative activity}

SKBR3, MDA-MB-453 and MDA-MB-231 were seeded on a monolayer 96-well plate at a density of about 6,000 cells/well for 24 hours before the experiment begins. After overnight attachment, cells were exposed continuously for 72 hours to docetaxel (0.01-100 nM) and trastuzumab (0.02-200 pM). Different conditions were tested: free docetaxel, free trastuzumab, free drugs (docetaxel plus free trastuzumab), Liposome-1 plus free trastuzumab, Liposome-2 plus free trastuzumab, ANC-1 and ANC-2. Cell viability was determined using the MTT assay and spectrophotometric reading at $550 \mathrm{~nm}$ (PowerWave XS2; BioTek, Saint-Jean-de-Védas, France).

\section{In vitro cellular uptake}

SKBR3, MDA-MB-453 and MDA-MB-231 were seeded on Lab-Tek chamber slides (Nunc, Roskilde, Denmark) at a density of about 20,000 cells/well for 24 hours before the experiment begins. After overnight attachment, cells were exposed continuously for 6 hours to DIR-labeled ANC-1 and labeled with Draq5. Next, cells were fixed with icecold methanol and incubated for 5 minutes at $-20^{\circ} \mathrm{C}$ before being rinsed with PBS. Cellular uptake was observed using confocal microscopy (TCS SP2 Leica) coupled to a digital camera.

\section{Statistical analysis}

In vitro experiment was performed at least in triplicate and data were represented as mean $\pm \mathrm{SD}$ or \pm standard error of the mean. Statistical analyses were performed on MedCalc 17.2.1. Software (MedCalc, Acacialaan, Belgium).

\section{Results}

\section{Size and polydispersity}

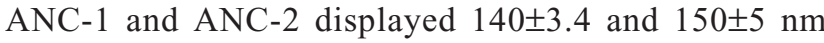
diameters, respectively. PDI was found to be much lower
Table I Summary of the different extrusion conditions tested on Liposome- ${ }^{\mathrm{a}}$

\begin{tabular}{llll}
\hline $\begin{array}{l}\text { Size reduction } \\
\text { technique }\end{array}$ & $\begin{array}{l}\text { Extrusion conditions } \\
\text { (amount of cycles and } \\
\text { type of filters used) }\end{array}$ & $\begin{array}{l}\text { Size } \\
\mathbf{( n m})\end{array}$ & PDI \\
\hline Extrusion & $2 \times 200 \mathrm{~nm}+4 \times 100 \mathrm{~nm}$ & $151 \pm 23$ & $0.088 \pm 0.04$ \\
Extrusion & $6 \times 100 \mathrm{~nm}$ & $141 \pm 4$ & $0.09 \pm 0.03$ \\
Extrusion & $4 \times 100 \mathrm{~nm}$ & $169 \pm 3$ & $0.13 \pm 0.02$ \\
Extrusion & $2 \times 100 \mathrm{~nm}+2 \times 80 \mathrm{~nm}$ & $133 \pm 2$ & $0.12 \pm 0.01$ \\
Extrusion & $2 \times 400 \mathrm{~nm}+2 \times 100 \mathrm{~nm}+$ & $135 \pm 3$ & $0.1 \pm 0.01$ \\
& $2 \times 80 \mathrm{~nm}$ & $141.4 \pm 9$ & $0.39 \pm 0.01$ \\
\hline
\end{tabular}

Note: ${ }^{a}$ Values are mean of three or more experiments.

Abbreviation: PDI, polydispersity index.

after extrusion as compared with sonication (ie, $0.11 \pm 0.02$ vs $0.39 \pm 0.001 ; p<0.001$, Student's $t$-test) and subsequent batches of liposomes were prepared by extrusion only (Table 1). With increasing number of extrusion cycles, both PDI and liposome size decreased (Table 1). Shifting from 4 to 6 extrusion cycles on $100 \mathrm{~nm}$ pore membranes led to $17 \%$ decrease in size with a 1.44-fold reduction in PDI. Use of $80 \mathrm{~nm}$ pore membrane led to a further $22 \%$ size reduction, without affecting PDI (Table 1). No significant difference in size was observed when adding upfront extrusions on $400 \mathrm{~nm}$ pore membrane (Table 1). Trastuzumab engraftment increased diameters of ANC- 1 and ANC- 2 by $9 \pm 4$ and $22 \pm 2 \mathrm{~nm}$, respectively (Table 2 ).

\section{Docetaxel encapsulation rate and entrapment efficiency}

Results of docetaxel encapsulation rate for Liposome-1 and Liposome-2 are summarized in Tables 3 and 4, respectively. Sonicated liposomes showed higher encapsulation rates as compared with liposomes obtained after extrusion (ie, $76 \% \pm 11 \%$ vs $35 \% \pm 19 \% ; p=0.037, t$-test). Adding PG to Liposome-1 composition increased docetaxel encapsulation rate from $35 \% \pm 19 \%$ to $63 \% \pm 18 \%$ (Table 3), with an optimal molar ratio of 50:19:15:1 (PC:Chol:PG:Mal-PEG). In these conditions, the $1.9 \%$ docetaxel: lipid molar ratio achieved the highest encapsulation rate as compared with $1.8 \%$ and $2.0 \%$ molar ratios (ie, $85 \% \pm 2 \%$ vs $70 \% \pm 19 \%$ vs $63 \% \pm 18 \%$, respectively, $p=0.244$, ANOVA test, Table 3 ). Adding PC to Liposome- 2 composition increased the encapsulation rate from $13 \% \pm 2 \%$ to $72 \% \pm 1 \%$, a value higher than the one obtained with DOTAP/Chol liposomes $(59 \% \pm 8 \%$, $p=0.032, t$-test, Table 4). Molar ratio of 50:19:15:1\%-1.9\% (PC:Chol:PG:Mal-PEG-docetaxel:lipid) for Liposome-1 and molar ratio of 18:17:1\%-5\% (DOTAP:PC:Mal-PEGdocetaxel:lipid) for Liposome-2 were selected to further 
Table 2 Characteristics of ANC-I and ANC-2 ${ }^{\mathrm{a}}$

\begin{tabular}{|c|c|c|c|c|c|c|c|}
\hline $\begin{array}{l}\text { Phospholipids } \\
\text { composition }\end{array}$ & $\begin{array}{l}\text { Molar } \\
\text { ratio }\end{array}$ & $\begin{array}{l}\text { Docetaxel:lipid } \\
\text { molar ratio (\%) }\end{array}$ & $\begin{array}{l}\text { Size reduction } \\
\text { technique }\end{array}$ & $\begin{array}{l}\text { Encapsulation } \\
\text { rate (\%) }\end{array}$ & $\begin{array}{l}\text { Encapsulation } \\
\text { efficiency (\%) }\end{array}$ & $\begin{array}{l}\text { Size } \\
(\mathrm{nm})\end{array}$ & PDI \\
\hline PC:Chol:PG:Mal-PEG & $50: 19: 15: 1$ & 1.9 & Extrusion & $73 \pm 6$ & $>90 \%$ & $140 \pm 3.4$ & $0.1 \pm 0.01$ \\
\hline DOTAP:PC:Mal-PEG & $18: 17: 1$ & 5.0 & Extrusion & $53 \pm 4$ & $>75 \%$ & $150 \pm 5$ & $0.13 \pm 0.05$ \\
\hline
\end{tabular}

Note: ${ }^{a}$ Values are mean of three or more experiments.

Abbreviations: ANC, antibody nanoconjugate; PDI, polydispersity index; PC, phosphatidylcholine; Chol, cholesterol; PG, phosphatidylglycerol; Mal-PEG, I,2-distearoyl-snglycero-3-phosphoethanolamine-N-[maleimide(polyethylene glycol)-2000]; DOTAP, I,2-dioleoyl-3-trimethylammonium-propane.

engraft trastuzumab and to generate ANC-1 and ANC-2, respectively. Their formulation and characteristics are summarized in Table 2. ANC-1 and ANC-2 exhibited docetaxel encapsulation rate of $73 \% \pm 6 \%$ and $53 \% \pm 4 \%$ respectively ( $p=0.003$, $t$-test, Table 2). Docetaxel entrapment efficiency was found to be significantly higher than encapsulation rates (ie, $>90 \%$ for ANC- 1 and $>75 \%$ for ANC-2, Table 2 ).

\section{Trastuzumab engraftment rate}

The two engraftment strategies (ie, targeting the amine [strategy A] and the thiol [strategy B] functions) were tested on Liposome-1 only. Electrophoresis gel was used to confirm trastuzumab engraftment, as shown in Figure S1. As previously described, ${ }^{32}$ engrafted trastuzumab showed a slightly larger molecular weight (S1-A5), compared to the native form (S1-A2 and A3). However, strategy A did not present this shift (S1-A7), suggesting that this method did not allow proper engraftment on the liposomes and therefore was not tested on Liposome-2. On Liposome-1, strategy B did present this shift (S1-B5 and B3) and was also validated on Liposome-2 (S1-B5). Trastuzumab engraftment rate was indirectly measured by Bradford assay and found to be $31 \% \pm 6 \%$, and $32 \% \pm 2 \%$ for ANC-1 and ANC-2, respectively.

\section{Electronic microscopy studies}

ANC-1 (Figure S2) and ANC-2 (Figure S3) showed spherical shapes of homogeneous size. Upon transmission electron microscopy imaging, mean diameters were $129 \pm 10 \mathrm{~nm}$ and
$144 \pm 31 \mathrm{~nm}$ for ANC-1 and ANC-2, respectively. Several lipid bilayers were also observed on Liposome-1 examined before extrusion step (Figure S4).

\section{Stability studies}

When monitoring docetaxel encapsulation rate over time (Figure 2), no significant differences were found between the storage conditions (ie, $-20^{\circ} \mathrm{C}, 4^{\circ} \mathrm{C}, 25^{\circ} \mathrm{C}$ ). ANC- 1 and ANC-2 showed docetaxel leakage, with a decrease in docetaxel of $19 \% \pm 20 \%$ and $48 \% \pm 19 \%$ per week, respectively $(p<0.001, t$-test). Size was regularly evaluated as well, until docetaxel reached 0\% (ie, 45 days for ANC-1, Figure S5, and 15 days for ANC-2, data not shown). No significant difference was observed in size between ANC-1 and ANC-2. When diluted or concentrated at $4^{\circ} \mathrm{C}$ or diluted at $25^{\circ} \mathrm{C}$, size was steady over time (Figure S5). Only ANC kept at $-20^{\circ} \mathrm{C}$ led to an increase in diameter over time. Within a week, size increased from $140 \pm 3$ to $220 \pm 25 \mathrm{~nm}$ for ANC-1 ( $p=0.004, t$-test) and from $158 \pm 13$ to $217 \pm 14 \mathrm{~nm}$ for ANC-2 ( $p=0.04, t$-test) before being stabilized. Trastuzumab engraftment was persistent after 45 days for ANC-1 (Figure S1-B7). Similar results were found with ANC-2 (data not shown).

\section{Quantification of HER2 on cells}

Flow cytometry analysis allowed measuring the expression of HER2 on the surface of every cell lines, with marked differences (Figure 3). Of note, it was possible to detect and

Table 3 Characteristics of liposome- $\left.\right|^{a}$

\begin{tabular}{llllll}
\hline $\begin{array}{l}\text { Phospholipids } \\
\text { composition }\end{array}$ & $\begin{array}{l}\text { Molar } \\
\text { ratio }\end{array}$ & $\begin{array}{l}\text { Docetaxel:lipid } \\
\text { molar ratio (\%) }\end{array}$ & $\begin{array}{l}\text { Encapsulation } \\
\text { rate (\%) }\end{array}$ & $\begin{array}{l}\text { Size reduction } \\
\text { technique }\end{array}$ \\
\hline PC:Chol:Mal-PEG & $50: 29: 1$ & 2.9 & $17 \pm 9$ & Extrusion & $141.7 \pm 2.3$ \\
PC:Chol:Mal-PEG & $50: 19: 1$ & 3.2 & $35 \pm 19$ & Extrusion & $175 \pm 31$ \\
PC:Chol:Mal-PEG & $50: 19: 1$ & 3.2 & $76 \pm 11$ & Sonication & $141.4 \pm 9$ \\
PC:Chol:PG:Mal-PEG & $50: 19: 15: 1$ & 1.8 & $70 \pm 19$ & Extrusion & - \\
PC:Chol:PG:Mal-PEG & $50: 19: 15: 1$ & 1.9 & $85 \pm 2$ & Extrusion & $141 \pm 2.4$ \\
PC:Chol:PG:Mal-PEG & $50: 19: 15: 1$ & 2.0 & $63 \pm 18$ & Extrusion & 158.8 \\
\hline
\end{tabular}

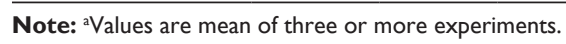

Abbreviations: PC, phosphatidylcholine; Chol, cholesterol; PG, phosphatidylglycerol; Mal-PEG, I,2-distearoyl-sn-glycero-3-phosphoethanolamine-N-[maleimide(polyethylene glycol)-2000]; PG, phosphatidylglycerol. 
Table 4 Characteristics of Liposome-2a

\begin{tabular}{llllll}
\hline $\begin{array}{l}\text { Phospholipids } \\
\text { composition }\end{array}$ & $\begin{array}{l}\text { Molar } \\
\text { ratio }\end{array}$ & $\begin{array}{l}\text { Docetaxel:lipid } \\
\text { molar ratio (\%) }\end{array}$ & $\begin{array}{l}\text { Encapsulation } \\
\text { rate (\%) }\end{array}$ & $\begin{array}{l}\text { Size reduction } \\
\text { technique }\end{array}$ & $\begin{array}{l}\text { Size } \\
(\mathbf{n m})\end{array}$ \\
\hline DOTAP:Mal-PEG & $47: 1$ & 10.0 & $13 \pm 2$ & Extrusion & $173 \pm 5$ \\
DOTAP:Chol:Mal-PEG & $34: 13: 1$ & 2.0 & $59 \pm 8$ & Extrusion & $134 \pm 7$ \\
DOTAP:Chol:Mal-PEG & $34: 13: 1$ & 4.3 & $58 \pm 3$ & Extrusion & $154 \pm 5$ \\
DOTAP:Chol:Mal-PEG & $49: 43: 1$ & 5.0 & $36 \pm 9$ & Extrusion & 150 \\
DOTAP:PC:Mal-PEG & $13: 22: 1$ & 3.7 & $49 \pm 12$ & Extrusion & $137 \pm 19$ \\
DOTAP:PC:Mal-PEG & $18: 17: 1$ & 5.0 & $72 \pm 1$ & Extrusion & $133 \pm 2$ \\
\hline
\end{tabular}

Note: ${ }^{a}$ Values are mean of three or more experiments.

Abbreviations: DOTAP, I,2-dioleoyl-3-trimethylammonium-propane; Mal-PEG, I,2-distearoyl-sn-glycero-3-phosphoethanolamine-N-[maleimide(polyethylene glycol)2000]; PG, phosphatidylglycerol; Chol, cholesterol; PC, phosphatidylcholine.

to quantify HER2 in MDA-MB-231 cells, despite their status of HER2-negative canonical model. SKBR3, MDA-MB-453 and MDA-MB-231 were found to express $1,117.10^{3} \pm 17.10^{3}$, $215.10^{3} \pm 37.10^{3}$ and $5.10^{3} \pm 0.3 .10^{3}$ HER2 receptors per cell, respectively ( $p<0.001$, one-way ANOVA, Figure 2).

\section{In vitro antiproliferative activity}

Results of cytotoxicity studies are summarized in Figure 4 (MDA-MB-231), Figure 4 (MDA-MB-453) and Figure 5 (SKBR3). As expected, both empty liposomes and single-agent trastuzumab ${ }^{46}$ showed no antiproliferative activity on our cell models (data not shown). The $\mathrm{IC}_{50 \mathrm{~s}}$ for docetaxel combined to free trastuzumab were $8.7 \pm 4,2 \pm 0.7$ and $6 \pm 2 \mathrm{nM}$ with MDA-MB-231, MDA-MB-453 and SKBR3, respectively. The $\mathrm{IC}_{50 \mathrm{~s}}$ for ANC-1 were $2.5 \pm 1,1.8 \pm 0.6$ and $3.4 \pm 0.8 \mathrm{nM}$ and for ANC-2 were $1.8 \pm 0.3,2.8 \pm 0.8$ and $6.8 \pm 1.8 \mathrm{nM}$ with MDA-MB-231, MDA-MB-453 and SKBR3, respectively. On MDA-MB-231 cells, reaching $\mathrm{IC}_{50}$ was achieved with $71 \%$ lower dose ( $p=0.029, t$-test $)$ as compared with free drugs for ANC-1 and $79 \%$ lower dose $(p=0.043, t$-test $)$ for
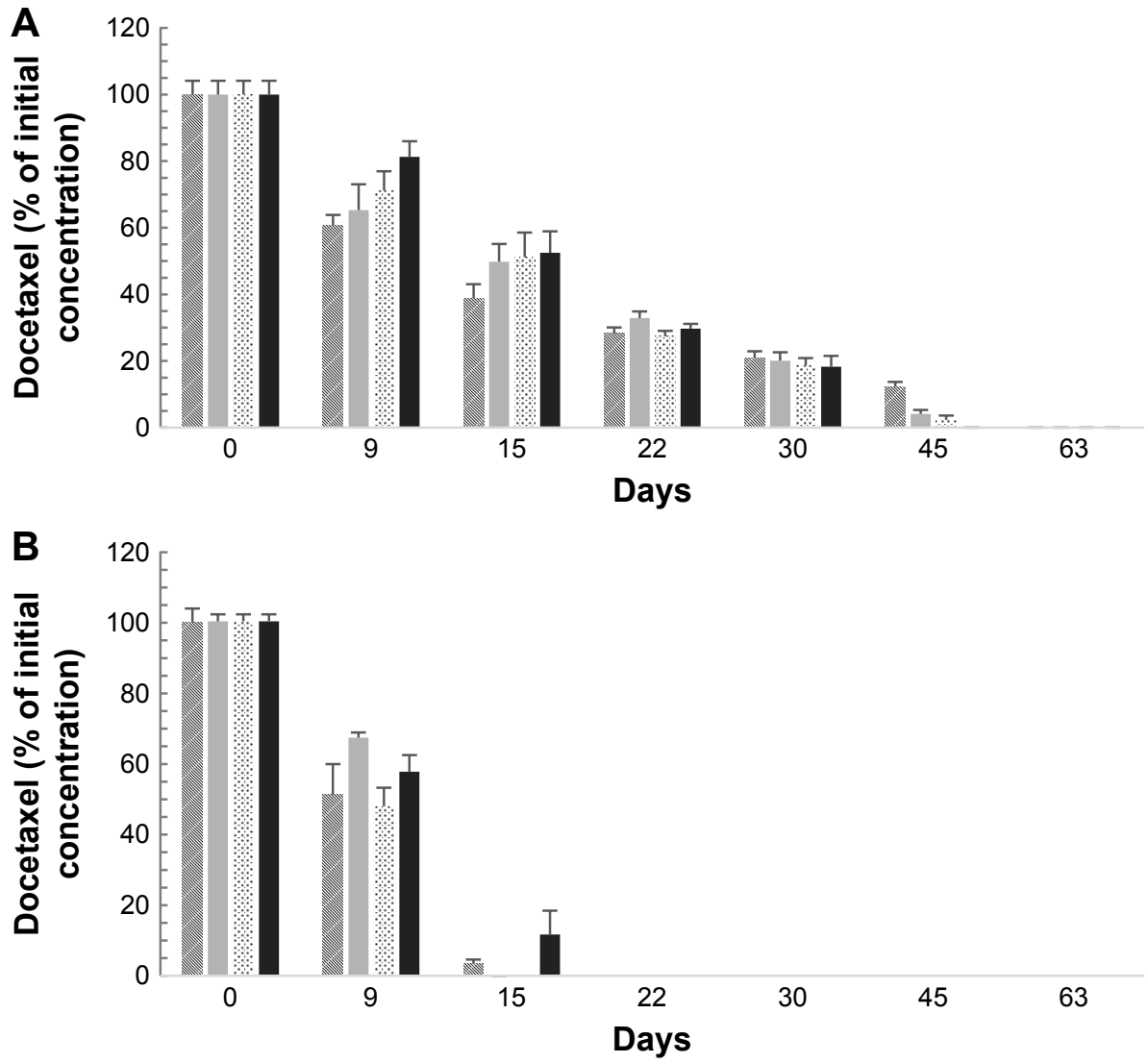

Figure 2 Monitoring of docetaxel encapsulation (\%) over time for ANC-I (A) and ANC-2 (B) following different storage conditions: diluted at $-20^{\circ} \mathrm{C}$ ( $\mathbf{}$ ), concentrated at $4^{\circ} \mathrm{C}(\mathbb{N})$, diluted at $4^{\circ} \mathrm{C}(\square)$ and diluted at $25^{\circ} \mathrm{C}()^{\mathrm{a}}$

Note: ${ }^{a}$ alues are mean \pm SEM of three or more experiments.

Abbreviation: ANC, antibody nanoconjugate. 

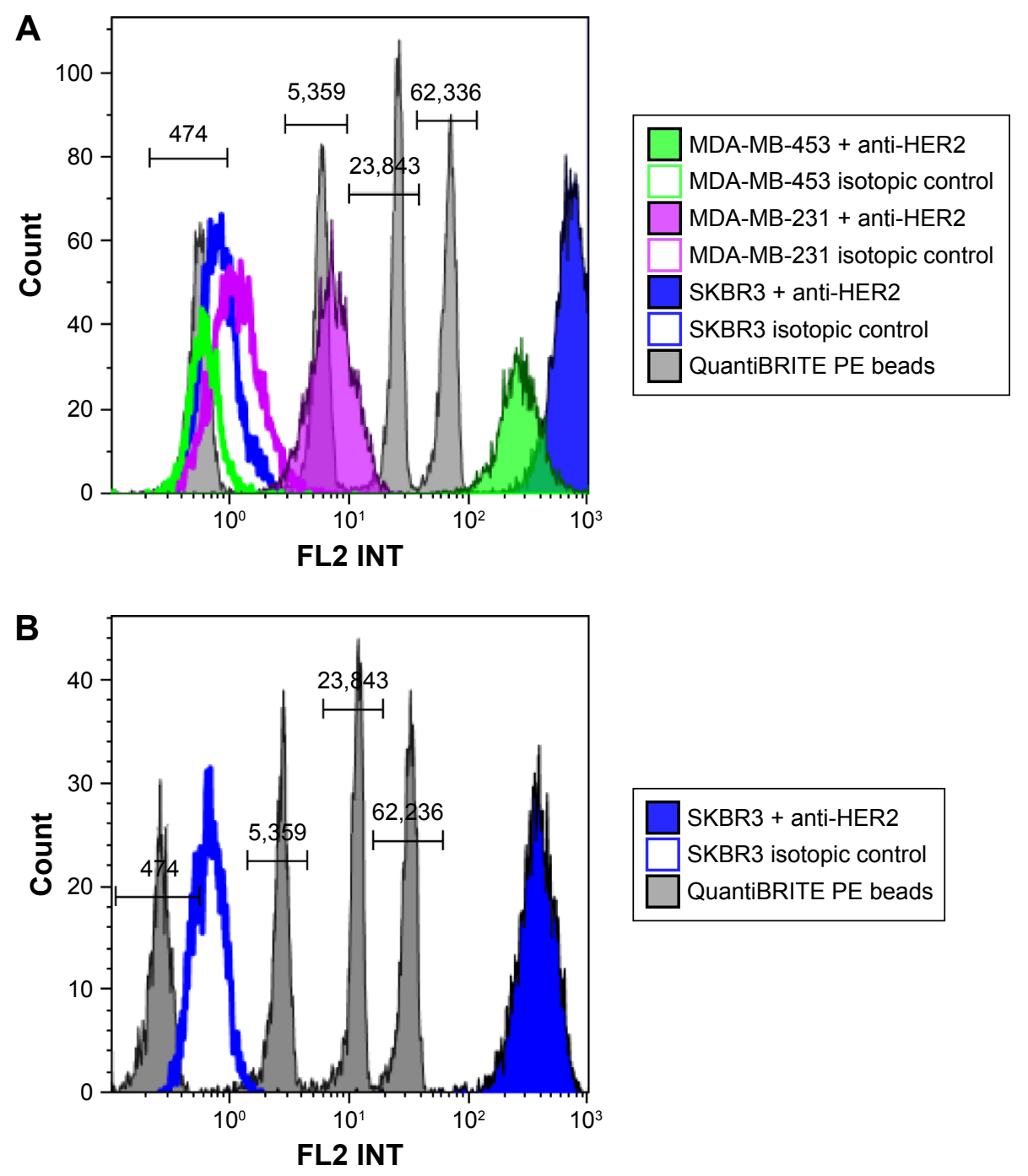

Figure 3 Quantification of HER2 using QuantiBRITE kit in standard conditions on MDA-MB-23I and MDA-MB-453 (A) and in lower intensity conditions on SKBR3 (B).

ANC-2 (Figure 5). For MDA-MB-453 and SKBR3, $\mathrm{IC}_{50}$ were reached using $8 \%(p=0.799$, $t$-test $)$ and $44 \%(p=0.2$, MannWhitney test) lower dose, respectively, for ANC-1 (Figure 6). Conversely with ANC-2, 38\% and 13\% higher dose were required to reach the $\mathrm{IC}_{50}$ with MDA-MB-453 and SKBR3 as compared with free drugs (Figure 6). Engrafting trastuzumab to liposomes (ie, ANC vs liposome) did not improve efficacy on in vitro 2D models, regardless of the cell lines (Figure 7).
A

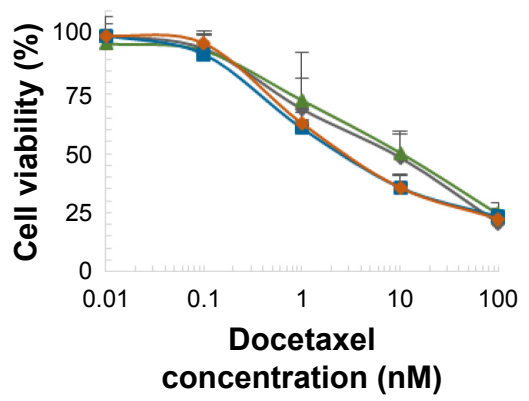

B

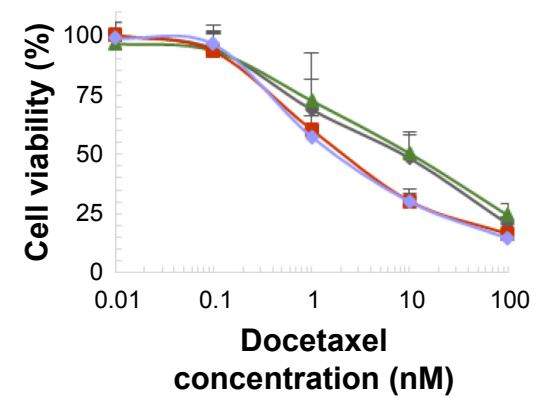

C

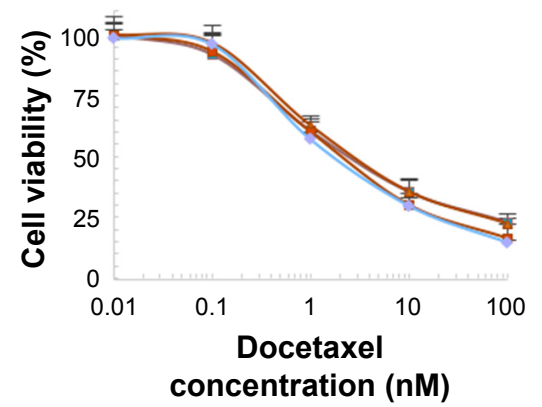

Figure 4 Cell viability $(\%)$ of MDA-MB-23I when exposed to free docetaxel $(\rightarrow-)$, free drugs $(-\rightarrow)$, Liposome-I plus free trastuzumab $(\rightarrow-)$, ANC-I $(\rightarrow-)$, Liposome-2 plus free trastuzumab $(-\rightarrow)$ and ANC-2 $(\multimap-)^{\text {a }}$

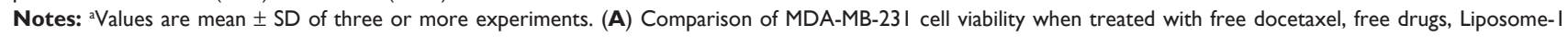
plus free trastuzumab or ANC-I. (B) Comparison of MDA-MB-23I cell viability when treated with free docetaxel, free drugs, Liposome-2 plus free trastuzumab or ANC-2. (C) Comparison of MDA-MB-23I cell viability when treated with Liposome-I plus free trastuzumab, ANC-I, Liposome-2 plus free trastuzumab or ANC-2.

Abbreviation: ANC, antibody nanoconjugate. 

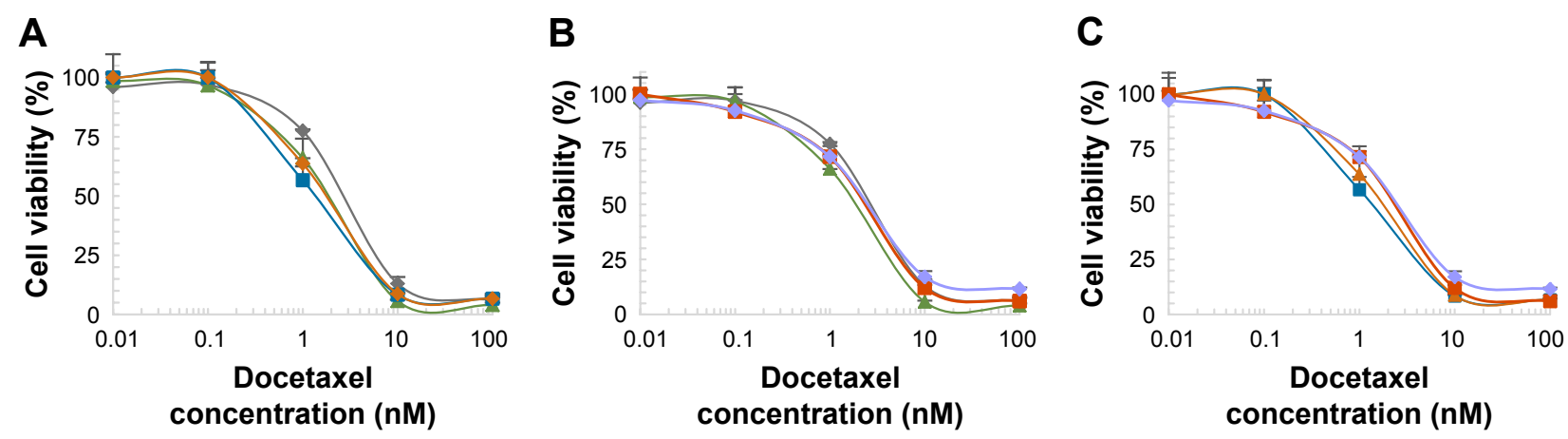

Figure 5 Cell viability $(\%)$ of MDA-MB-453 when exposed to free docetaxel $(\rightarrow-)$, free drugs $(\rightarrow)$, Liposome-I plus free trastuzumab $(\rightarrow-)$, ANC-I $(\rightarrow-)$, Liposome-2 plus free trastuzumab $(--)$ and ANC-2 $(\multimap,)^{\mathrm{a}}$

Notes: ${ }^{\vee}$ Values are mean \pm SD of three or more experiments. (A) Comparison of MDA-MB-453 cell viability when treated with free docetaxel, free drugs, Liposome-I plus free trastuzumab or ANC-I. (B) Comparison of MDA-MB-453 cell viability when treated with free docetaxel, free drugs, Liposome-2 plus free trastuzumab or ANC-2. (C) Comparison of MDA-MB-453 cell viability when treated with Liposome-I plus free trastuzumab, ANC-I, Liposome-2 plus free trastuzumab or ANC-2.

Abbreviation: ANC, antibody nanoconjugate.

\section{In vitro cellular uptake}

After 6 hours, cellular uptake of ANC-1 was observed in all cell models. ANC-1 was primarily localized around cell nucleus. Upon observation, ANC-1 seemed to better accumulate in SKBR3 than in MDA-MB-453, and in MDAMB-453 than in MDA-MB-231 (Figure 8A-C). Although not quantitative, a trend toward a relationship between HER2 expression rate and ANC-1 cellular uptake was observed.

\section{Discussion}

Improving drug delivery is a promising strategy to optimize anticancer drug efficacy while limiting treatment-related toxicities. ${ }^{47}$ Nanoparticles can accumulate in tumor surroundings via the enhanced permeation and retention (EPR) effect, helping cytotoxics to better trafficking to tumor tissues eventually. ${ }^{34}$ Here, we have developed novel and innovative immunoliposomes coupling docetaxel and trastuzumab to be used in breast cancer models. Simple and rapid thin-film method was used to synthesize stealth liposomes of docetaxel, making the production of the nanoparticles simple, cheap and reliable throughout time. Trastuzumab, used as a targeting agent towards HER2, was best engrafted via sulfhydryl groups on maleimide polyethylene glycol. Several formulations were tested and optimized, focusing on docetaxel encapsulation rate, size and polydispersity as endpoints. Required size has to be below $200 \mathrm{~nm}$ indeed to benefit from passive targeting through the EPR effect, ${ }^{33,34}$ the smaller the liposome, the higher specificity. ${ }^{48}$ Here, extrusion and sonication techniques were both tested to reduce liposome diameter. Extrusion generated a loss of volume, affecting docetaxel encapsulation rate when compared to sonication; however, extrusion was finally preferred because of better homogeneity in size. Two extrusion cycles on 400,100 , and $80 \mathrm{~nm}$ pore membranes were considered as the best compromise between adequate size, PDI and encapsulation rate. ANC-1 and ANC-2 displayed a size of $140 \pm 3.4$ and $150 \pm 5 \mathrm{~nm}$, respectively. Engrafting trastuzumab slightly reduced docetaxel encapsulation rates. This decrease could be explained by weakening of liposomes during stirring. Finally, ANC-1 presented a $20 \% \pm 10 \%$ higher docetaxel encapsulation rate than ANC-2. The engraftment
A

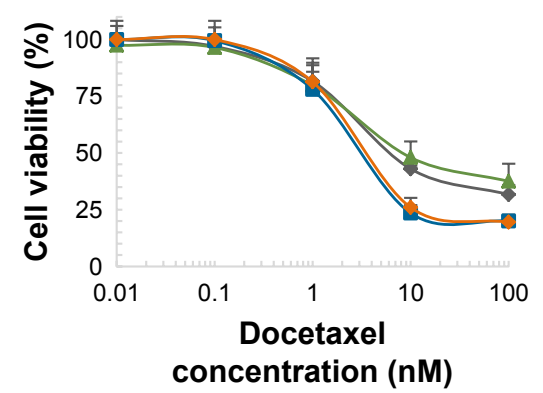

B

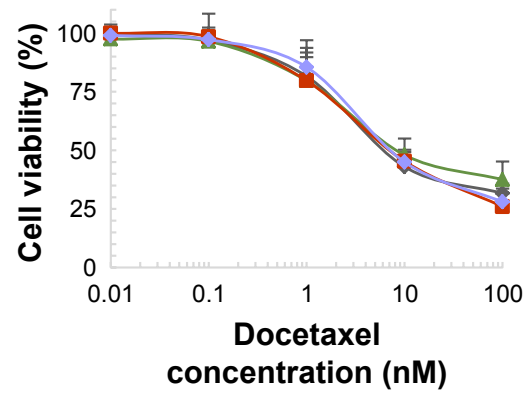

C

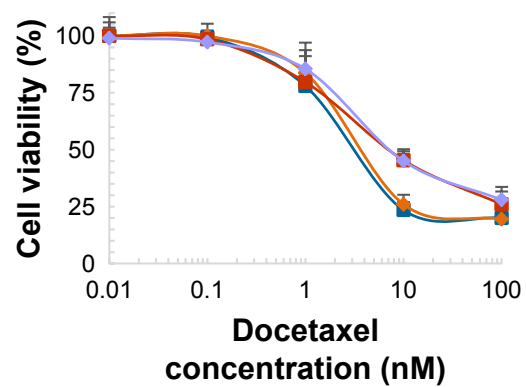

Figure 6 Cell viability $(\%)$ of SKBR3 when exposed to free docetaxel $(\rightarrow-)$, free drugs $(-\rightarrow)$, Liposome-I plus free trastuzumab $(\rightarrow-)$, ANC-I $(\rightarrow-)$, Liposome-2 with free trastuzumab $(--)$ and ANC-2 $(-)$.

Notes: ${ }^{2}$ Values are mean \pm SD of three or more experiments. (A) Comparison of SKBR3 cell viability when treated with free docetaxel, free drugs, Liposome-I plus free trastuzumab or ANC-I. (B) Comparison of SKBR3 cell viability when treated with free docetaxel, free drugs, Liposome-2 plus free trastuzumab or ANC-2. (C) Comparison of SKBR3 cell viability when treated with Liposome-I plus free trastuzumab, ANC-I, Liposome-2 plus free trastuzumab or ANC-2.

Abbreviation: ANC, antibody nanoconjugate. 


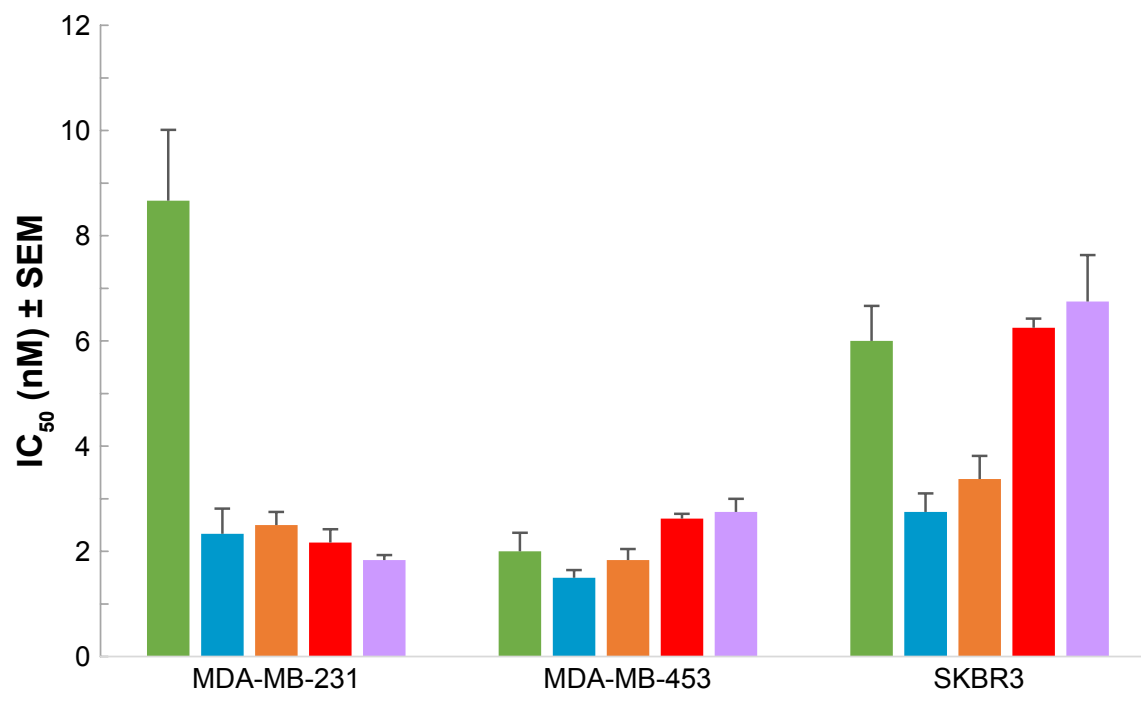

Figure 7 Modulation of docetaxel IC 50 of MDA-MB-23I, MDA-MB-453 and SKBR3 when treated for 72 hours with free drugs ( $\square$ ), Liposome-I ( $\square$ ), ANC-I ( $\square$ ), Liposome-2 $(\square)$ and ANC-2 ( $\square)^{\mathrm{a}}$

Note: ${ }^{V}$ alues are mean \pm SEM of three or more experiments.

Abbreviation: ANC, antibody nanoconjugate.

rate was similar for both compositions and in line with previous works. ${ }^{40}$ Stability studies showed that shelf conditions could be indistinctively $4^{\circ} \mathrm{C}$ or $25^{\circ} \mathrm{C}$, protected from light, for up to 1 week. ANC size remained steady with no signs of coalescence. However docetaxel concentration decreased rapidly (ie, 19\% decrease after 1 week for ANC-1). ANC-2 was found to be even less stable, probably because of the absence of cholesterol ${ }^{49}$ resulting in higher docetaxel leakage. Consequently, extemporaneous preparation was required to perform in vitro studies. In the future, lyophilization could be an interesting strategy to fix the issue of storage and drug leakage, ${ }^{12}$ although preliminary studies suggest that it may lead to an increase in size (data not shown). Future plans include use of sugar derivatives as cryoprotector, as a means to stabilize the nanoparticle during the lyophilization phase.

Human MDA-MB-231, MDA-MB-453 and SKBR3 cell lines were chosen as cancer model because of marked variations in HER2 expression. Of note, although MDA-MB-231 are usually presented as a canonical triple negative model, we were able to detect HER2 expression with this cell line, which is markedly lower as compared with MDA-MB-453 and SKBR3 cells. As expected, empty liposomes and trastuzumab alone did not show any antiproliferative effect. Combining docetaxel with trastuzumab led to a significant increase of sensitivity for MDA-MB-453 cells when compared to free
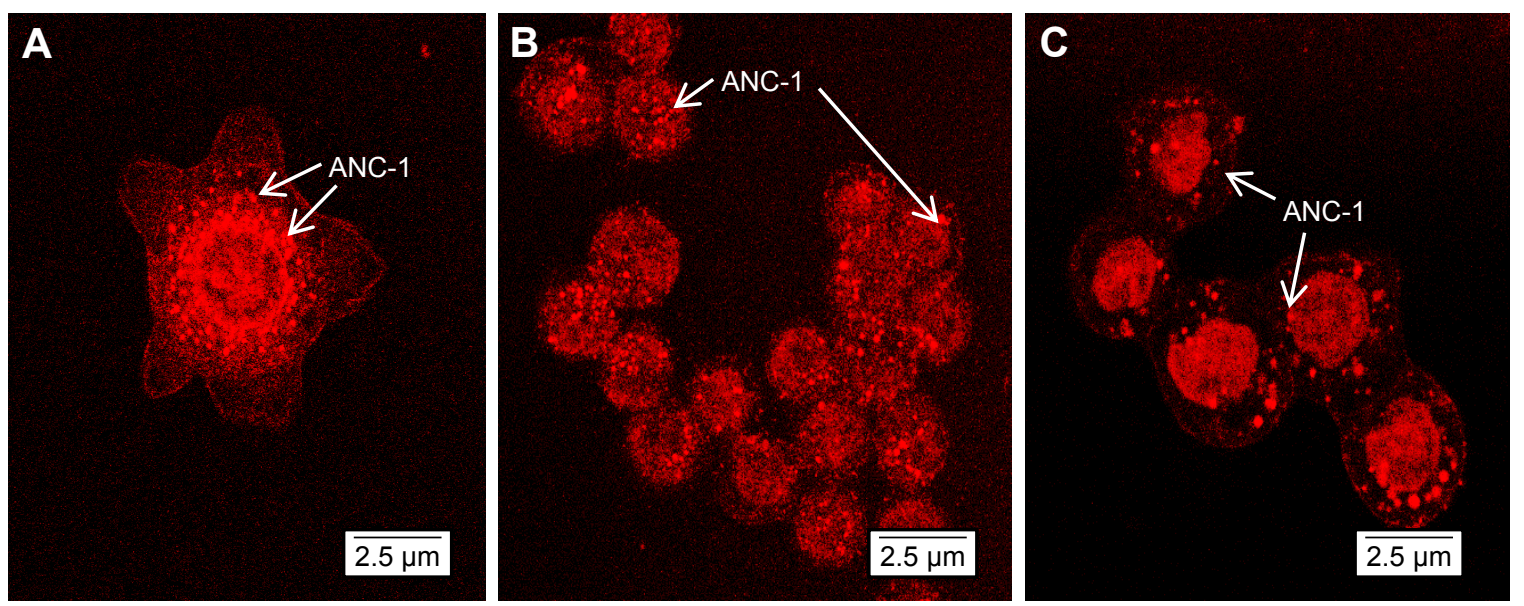

Figure 8 Confocal microscopy observations of ANC-I uptake on SKBR3 (A), MDA-MB-453 (B) and MDA-MB-23I (C) cells, after 6 hour exposition. Note: Magnification $\times 40$.

Abbreviation: ANC, antibody nanoconjugate. 
docetaxel only. MDA-MB-231 (HER2 \pm ) and MDA-MB-453 (HER2+) were found to be the most resistant and the most sensitive to free drugs, respectively, an observation in line with differences in HER2 expression between these cells. Encapsulating docetaxel in ANC-1 led to an increased efficacy on MDA-MB-231, SKBR3 and MDA-MB-453. Encapsulating docetaxel in ANC-2 led to an improved efficacy on MDA-MB-231 only. Overall, both liposomal docetaxel and ANC showed improved efficacy in resistant tumor cells, suggesting a better ability to circumvent drug resistance using nanoparticles. No significant difference was observed between Liposome-1 plus free trastuzumab and Liposome-2 plus free trastuzumab when compared to ANC-1 and ANC-2, suggesting that $2 \mathrm{D}$ antiproliferative experiments as we performed may not properly address the issue of immunoliposomes efficacy. ${ }^{7}$ Indeed, because monoclonal antibodies barely diffuse within tissues and tumors, the benefit from engrafting trastuzumab to a highly lipophilic nanoparticle can be hardly evidenced using models of monolayer cancer cells. Here, the expected benefit with immunoliposomes is based upon the hypothesis that when engrafted to a liposome, the antibody will more easily penetrate deep into the tumor mass, rather than being restricted to hitting targets of the external layer of cells. Spheroids or organoids should therefore be used in the future to better compare the performances of immunoliposomes with that of standard cytotoxics + monoclonal antibody combination. Because of its specific composition, ANC-1 exhibited better performances in terms of size, encapsulation rates, stability and in vitro activity as compared with ANC-2. Therefore, ANC-1 only was selected for further analysis of cellular uptake. Interestingly, cellular uptake was different depending on the cell line, an observation in line with measurement of HER 2 expression between MDA-MB-231, MDA-MB-453 and SKBR3 breast cancer cells, the higher the expression, the higher the uptake. Differences in cell uptake are not consistent with differences in efficacy observed during antiproliferative activity testing, but this discrepancy could be due to differences in timing between uptake studies (6H) and the endpoint of efficacy studies $(72 \mathrm{H})$. Overall, the early data we generated indicate that redesigning an approved combo (ie, trastuzumab + docetaxel administrated separately) as a single nanoparticle is feasible and exhibits promising antiproliferative efficacy in a variety of cancer models. Targeting HER2+ breast cancer with nanomedicine is certainly not new and several studies with polymeric micelles encapsulating HSP90 inhibitor, paclitaxel and trastuzumab have shown excellent efficacy, both in vitro and in tumor-bearing mice. ${ }^{48}$ Of note, HSP inhibition could further help HER2-targeting carriers to better trafficking inside cancer cells through extra-lysosomal targeting, thus enabling a better internalization of the nanoparticle-HER2 complex. ${ }^{49}$ The extent of adding a HSP inhibitor to the design of our ANC will have to be evaluated to further optimize drug delivery to HER2+ cancer cells.

\section{Conclusion}

In this work, we demonstrated the feasibility of making 3rd generation liposomes in breast cancer, using a cheap and rapid process. Development showed that composition of the liposomes has a strong impact on subsequent characteristics and performance. Although preliminary and still showing several caveats (eg, stability limited to 1 week) that require to be addressed, in vitro results are promising and suggest that delivering cytotoxics plus biologics could be optimized when administered as immunoliposomes, rather than as free drugs.

\section{Acknowledgments}

The authors would like to thank the platform Amuticyt (VRCM) de la faculté de Pharmacie La Timone and the Service Commun de Microscopie Électronique de la Faculté de Médecine La Timone for their technical expertise. The authors would also like to thank the Ligue Contre le Cancer who generously provided a grant to AR. Additionally, we thank the French Institut Roche who partly supported this study and Genentech who kindly provided trastuzumab.

\section{Author contributions}

AR, RF, JC, SG, JMB, HM, FC, EM and CO performed the bench experiments. AR, RF and JC performed statistical analyses. AR, RF, BL, AS, FB and JC wrote the manuscript. All authors contributed toward data analysis, drafting and revising the paper and agree to be accountable for all aspects of the work.

\section{Disclosure}

AS and FB are members of the Institut Roche, a joint-institute from Roche Laboratories that commercializes trastuzumab and has partly funded this study. JC and RF received fees as board members of Roche. The authors report no other conflicts of interest in this work.

\section{References}

1. McGrogan BT, Gilmartin B, Carney DN, McCann A. Taxanes, microtubules and chemoresistant breast cancer. Biochim Biophys Acta. 2008;1785(2):96-132.

2. Braakhuis BJ, Hill BT, Dietel M, et al. In vitro antiproliferative activity of docetaxel (Taxotere), paclitaxel (Taxol) and cisplatin against human tumour and normal bone marrow cells. Anticancer Res. 1994 14(1A):205-208. 
3. Jones SE, Erban J, Overmoyer B, et al. Randomized phase III study of docetaxel compared with paclitaxel in metastatic breast cancer. J Clin Oncol. 2005;23(24):5542-5551.

4. Denman JP, Gilbar PJ, Abdi EA. Hypersensitivity reaction (HSR) to docetaxel after a previous HSR to paclitaxel. J Clin Oncol. 2002; 20(11):2760-2761.

5. Immordino ML, Brusa P, Arpicco S, Stella B, Dosio F, Cattel L. Preparation, characterization, cytotoxicity and pharmacokinetics of liposomes containing docetaxel. J Control Release. 2003;91(3):417-429.

6. Straubinger RM, Balasubramanian SV. Preparation and characterization of taxane-containing liposomes. Methods in Enzymology. 2005;391:97-117.

7. Pereira S, Egbu R, Jannati G, Al-Jamal WT. Docetaxel-loaded liposomes: the effect of lipid composition and purification on drug encapsulation and in vitro toxicity. Int J Pharm. 2016;514(1):150-159.

8. Yoshizawa Y, Kono Y, Ogawara K, Kimura T, Higaki K. PEG liposomalization of paclitaxel improved its in vivo disposition and anti-tumor efficacy. Int J Pharm. 2011;412(1-2):132-141.

9. Su W, Zhang S, Li C, Hao X, Zhang J. [Efficacy and safety analysis of paclitaxel liposome and docetaxel for the neoadjuvant chemotherapy of breast cancer]. Zhonghua Zhong Liu Za Zhi. 2015;37(5):379-382. Chinese [with English abstract].

10. Wang HY, Zhang XR. Comparison of efficacy and safety between liposome-paclitaxel injection plus carboplatin and paclitaxel plus carboplatin as first line treatment in advanced non-small cell lung cancer. Zhongguo Yi Хuе Ke Xue Yuan Xие Bao. 2014;36(3):305-308.

11. Deeken JF, Slack R, Weiss GJ, et al. A phase I study of liposomalencapsulated docetaxel (LE-DT) in patients with advanced solid tumor malignancies. Cancer Chemother Pharmacol. 2013;71(3):627-633.

12. Chen Y, Chen J, Cheng Y, et al. A lyophilized sterically stabilized liposome-containing docetaxel: in vitro and in vivo evaluation. J Liposome Res. 2017;27(1):64-73.

13. Xu Y, Meng H. Paclitaxel-loaded stealth liposomes: development, characterization, pharmacokinetics, and biodistribution. Artif Cells Nanomed Biotechnol. 2016;44(1):350-355.

14. Wang X, Zhou J, Wang Y, et al. A phase I clinical and pharmacokinetic study of paclitaxel liposome infused in non-small cell lung cancer patients with malignant pleural effusions. Eur J Cancer. 2010;46(8): 1474-1480.

15. Li J, Guo C, Feng F, et al. Co-delivery of docetaxel and palmitoyl ascorbate by liposome for enhanced synergistic antitumor efficacy. Sci Rep. 2016;6:38787.

16. Eloy JO, Petrilli R, Topan JF, et al. Co-loaded paclitaxel/rapamycin liposomes: development, characterization and in vitro and in vivo evaluation for breast cancer therapy. Colloids Surf B Biointerfaces. 2016; 141:74-82.

17. Qu MH, Zeng RF, Fang S, Dai QS, Li HP, Long JT. Liposome-based co-delivery of siRNA and docetaxel for the synergistic treatment of lung cancer. Int J Pharm. 2014;474(1-2):112-122.

18. Chang M, Lu S, Zhang F, et al. RGD-modified $\mathrm{pH}$-sensitive liposomes for docetaxel tumor targeting. Colloids Surf B Biointerfaces. 2015;129: $175-182$.

19. Ranjan A, Benjamin CJ, Negussie AH, et al. Biodistribution and efficacy of low temperature-sensitive liposome encapsulated docetaxel combined with mild hyperthermia in a mouse model of prostate cancer. Pharm Res. 2016;33(10):2459-2469.

20. Liang Z, Yang N, Jiang Y, et al. Targeting docetaxel-PLA nanoparticles simultaneously inhibit tumor growth and liver metastases of small cell lung cancer. Int J Pharm. 2015;494(1):337-345.

21. Li X, Zhang J, Wang DK, Pan WS. [Anti-tumor activity of folate receptor targeting docetaxel-loaded membrane-modified liposomes]. Yao Xиe Хие Bao. 2013;48(7):1142-1147. Chinese [with English abstract].

22. Tong L, Chen W, Wu J. Li H. Folic acid-coupled nano-paclitaxel liposome reverses drug resistance in SKOV3/TAX ovarian cancer cells. Anticancer Drugs. 2014;25(3):244-254.

23. Chen L, Liu Y, Wang W, Liu K. Effect of integrin receptor-targeted liposomal paclitaxel for hepatocellular carcinoma targeting and therapy. Oncol Lett. 2015;10(1):77-84.
24. Yuan MQ, Zhu F, Lou JY, et al. The anti-tumoral efficacy of a docetaxelloaded liposomal drug delivery system modified with transferrin for ovarian cancer. Drug Res (Stuttg). 2014;64(4):195-202.

25. Zhai G, Wu J, Yu B, Guo C, Yang X, Lee RJ. A transferrin receptortargeted liposomal formulation for docetaxel. J Nanosci Nanotechnol. 2010;10(8):5129-5136.

26. Mamot C, Ritschard R, Wicki A, et al. Tolerability, safety, pharmacokinetics, and efficacy of doxorubicin-loaded anti-EGFR immunoliposomes in advanced solid tumours: a phase 1 dose-escalation study. Lancet Oncol. 2012;13(12):1234-1241.

27. Hynes NE, Stern DF. The biology of erbB-2/neu/HER-2 and its role in cancer. Biochim Biophys Acta. 1994;1198(2-3):165-184.

28. LoRusso P, Krop I, Miller K, et al. A phase I study of MM-302, a HER2-targeted PEGylated liposomal doxorubicin, in patients with HER2+ metastatic breast cancer. Cancer Res. 2015;75(15):abstract CT234.

29. ADC Review. MM-302 Misses Endpoint in Phase II Hermione Trial. 2016. Available from: https://adcreview.com/news/mm-302-missesendpoint-phase-ii-hermione-trial/. Accessed July 27, 2017.

30. Marty M, Cognetti F, Maraninchi D, et al. Randomized phase II trial of the efficacy and safety of trastuzumab combined with docetaxel in patients with human epidermal growth factor receptor 2-positive metastatic breast cancer administered as first-line treatment: the M77001 study group. J Clin Oncol. 2005;23(19):4265-4274.

31. Metro G, Mottolese M, Fabi A. HER-2-positive metastatic breast cancer: trastuzumab and beyond. Expert Opin Pharmacother. 2008; 9:2583-2601.

32. Gao J, Sun J, Li H, et al. Lyophilized HER2-specific PEGylated immunoliposomes for active siRNA gene silencing. Biomaterials. 2010; 31(9):2655-2664.

33. Bangham AD, Standish MM, Watkins JC. Diffusion of univalent ions across the lamellae of swollen phospholipids. J Mol Biol. 1965; 13(1):238-252.

34. Maeda H. The enhanced permeability and retention (EPR) effect in tumor vasculature: the key role of tumor-selective macromolecular drug targeting. Adv Enzyme Regul. 2001;41:189-207.

35. Sawant RR, Torchilin VP. Challenges in development of targeted liposomal therapeutics. AAPS J. 2012;14(2):303-315.

36. Thermo scientific pierce crosslinking technical handbook.pdf.

37. Choi WI, Lee JH, Kim JY, et al. Targeted antitumor efficacy and imaging via multifunctional nano-carrier conjugated with anti-HER2 trastuzumab. Nanomedicine. 2015;11(2):359-368.

38. Zhou Z, Badkas A, Stevenson M, Lee JY, Leung YK. Herceptin conjugated PLGA-PHis-PEG pH sensitive nanoparticles for targeted and controlled drug delivery. Int J Pharm. 2015;487(1-2):81-90.

39. Shariat S, Badiee A, Jaafari MR, Mortazavi SA. Optimization of a method to prepare liposomes containing HER2/Neu- derived peptide as a vaccine delivery system for breast cancer. Iran J Pharm Res. 2014; 13(Suppl):15-25.

40. Soema PC, Willems GJ, Jiskoot W, Amorij JP, Kersten GF. Predicting the influence of liposomal lipid composition on liposome size, zeta potential and liposome-induced dendritic cell maturation using a design of experiments approach. Eur J Pharm Biopharm. 2015;94: 427-435.

41. Garg MB, Ackland SP. Simple and sensitive high-performance liquid chromatography method for the determination of docetaxel in human plasma or urine. J Chromatogr B Biomed Sci Appl. 2000;748(2): 383-388.

42. Bradford MM. A rapid and sensitive method for the quantitation of microgram quantities of protein utilizing the principle of protein-dye binding. Anal Biochem. 1976;72:248-254.

43. Hultin LE, Matud JL, Giorgi JV. Quantitation of CD38 activation antigen expression on CD8+ T cells in HIV-1 infection using CD4 expression on CD4+ T lymphocytes as a biological calibrator. Cytometry. 1998;33(2):123-132.

44. Hurrell T, Outhoff K. The in vitro influences of epidermal growth factor and heregulin- $\beta 1$ on the efficacy of trastuzumab used in Her- 2 positive breast adenocarcinoma. Cancer Cell Int. 2013;13(1):97. 
45. Bregoli L, Movia D, Gavigan-Imedio JD, Lysaght J, Reynolds J, PrinaMello A. Nanomedicine applied to translational oncology: a future perspective on cancer treatment. Nanomedicine. 2016;12(1):81-103.

46. Fanciullino R, Mollard S, Correard F, et al. Biodistribution, tumor uptake and efficacy of 5-FU-loaded liposomes: why size matters. Pharm Res. 2014;31(10):2677-2684.

47. Bitounis D, Fanciullino R, Iliadis A, Ciccolini J. Optimizing druggability through liposomal formulations: new approaches to an old concept. ISRN Pharm. 2012;2012:738432.
48. Soni KS, Lei F, Desale SS, Marky LA, Cohen SM, Bronich TK. Tuning polypeptide-based micellar carrier for efficient combination therapy of ErbB2-positive breast cancer. J Control Release . 2017;264:276-287.

49. Raja SM, Desale SS, Mohapatra B, et al. Marked enhancement of lysosomal targeting and efficacy of ErbB2-targeted drug delivery by HSP90 inhibition. Oncotarget. 2016;7(9):10522-10535. 


\section{Supplementary materials}
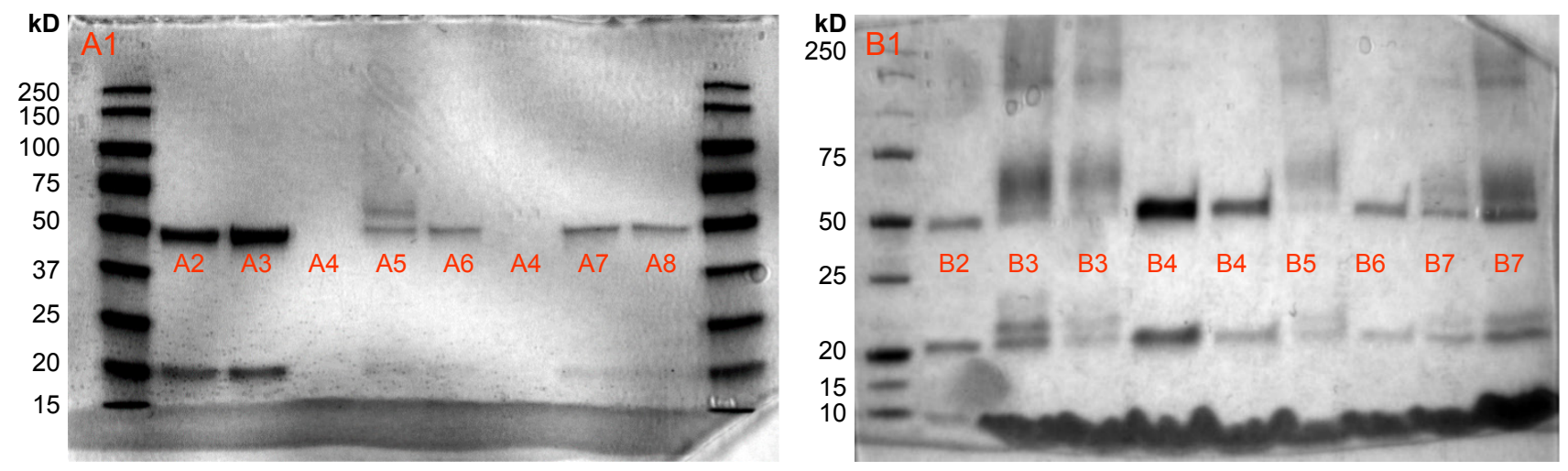

Figure SI Representative SDS-PAGE gel, showing trastuzumab engraftment on liposome surface. Protein markers (AI), trastuzumab (A2), thiolated trastuzumab (A3), Liposome-I (A4), ANC-I engrafted with strategy B (A5), Liposome-I engrafted with strategy $B$ without maleimide function (A6), ANC-I engrafted following strategy A (A7), Liposome-I engrafted following strategy $A$ without maleimide function (A8), protein markers (BI), trastuzumab (B2), ANC-I engrafted following strategy $B$ (B3), Liposome-I engrafted following strategy $B$ without maleimide function (B4), ANC-2 engrafted with strategy B (B5), Liposome-2 engrafted with strategy $B$ without maleimide function (B6), ANC-I engrafted with strategy B after 45 days (B7).

Abbreviations: SDS-PAGE, sodium dodecyl sulfate polyacrylamide gel electrophoresis; ANC, antibody nanoconjugate.
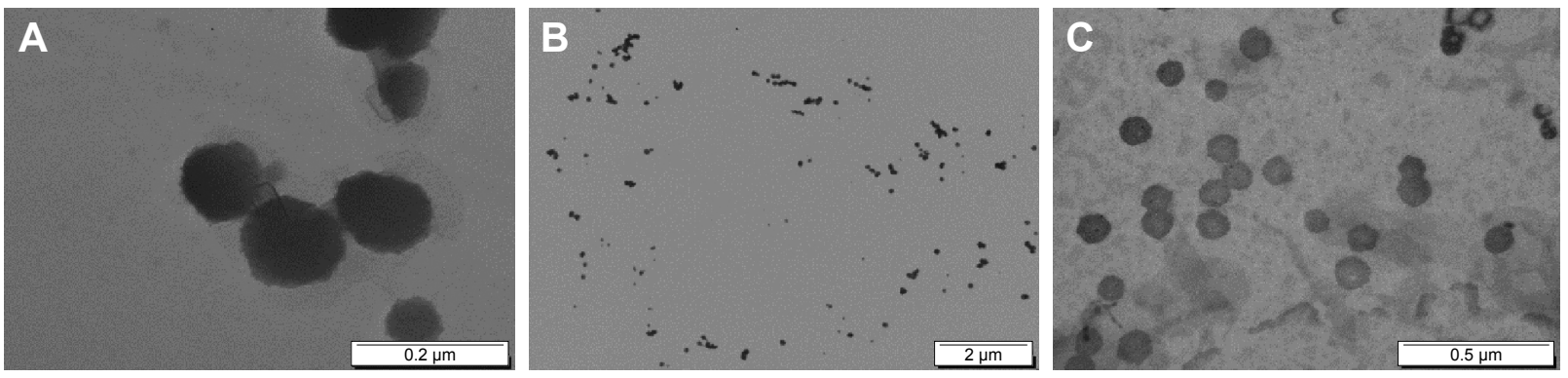

Figure S2 TEM observations of ANC-I treated with osmium tetroxide ( $\mathbf{A}$ and $\mathbf{B})$ and uranyl acetate (C). Abbreviations: TEM, transmission electron microscopy; ANC-I, antibody nanoconjugate-I.
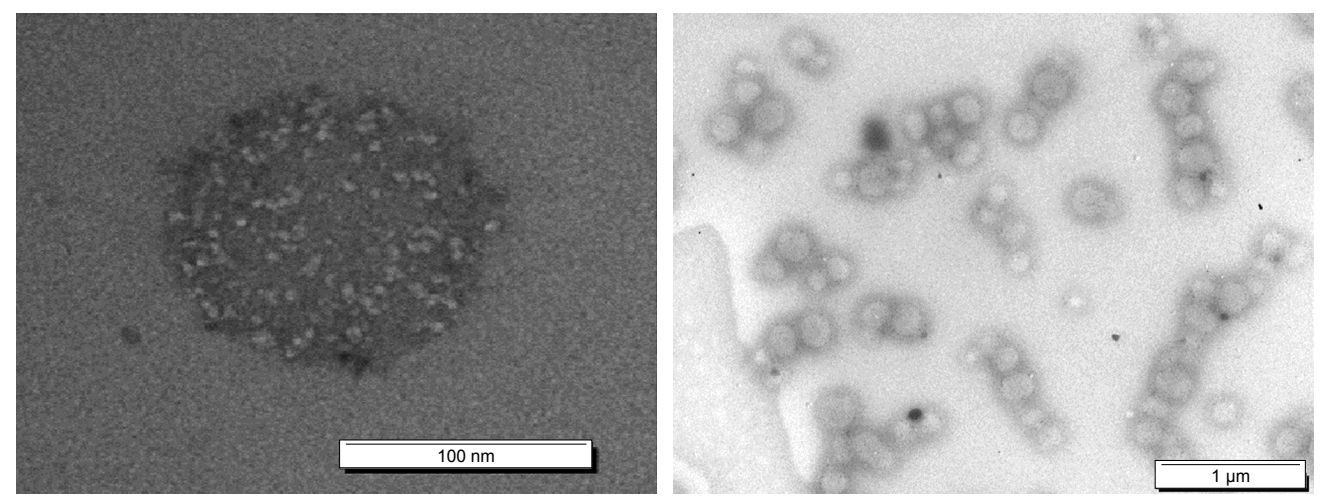

Figure S3 TEM observations of ANC-2 treated with osmium tetroxide.

Abbreviations: TEM, transmission electron microscopy; ANC-2, antibody nanoconjugate- 2 . 

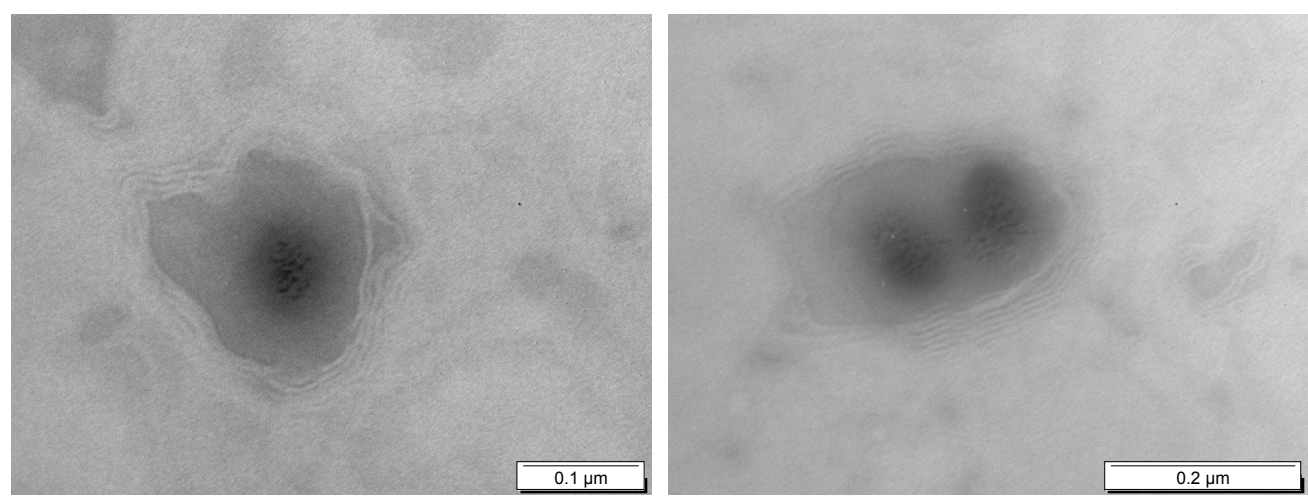

Figure S4 TEM observations of liposome-I before extrusion.

Abbreviation: TEM, transmission electron microscopy.

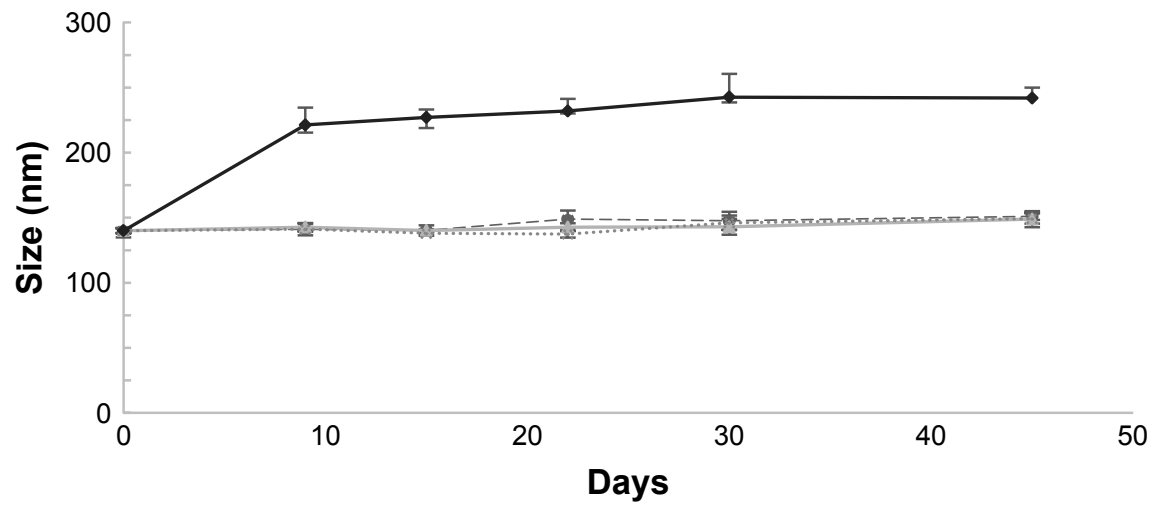

Figure S5 Monitoring size $(\mathrm{nm})$ over time for ANC-I following different storage conditions: diluted at $-20^{\circ} \mathrm{C}(\longrightarrow-)$, concentrated at $4^{\circ} \mathrm{C}(---)$, diluted at $4^{\circ} \mathrm{C}(-\rightarrow)$ and diluted at $25^{\circ} \mathrm{C}(\cdots \cdots) \cdot{ }^{a}$

Note: ${ }^{\mathrm{V}} \mathrm{V}$ alues are mean \pm SEM of three or more experiments.

Abbreviation: ANC-I, antibody nanoconjugate-I.

\section{Publish your work in this journal}

The International Journal of Nanomedicine is an international, peerreviewed journal focusing on the application of nanotechnology in diagnostics, therapeutics, and drug delivery systems throughou the biomedical field. This journal is indexed on PubMed Central, MedLine, CAS, SciSearch $®$, Current Contents $\AA /$ Clinical Medicine,
Journal Citation Reports/Science Edition, EMBase, Scopus and the Elsevier Bibliographic databases. The manuscript management system is completely online and includes a very quick and fair peer-review system, which is all easy to use. Visit http://www.dovepress.com/ testimonials.php to read real quotes from published authors. 